3 To cite this article: Mathias, S., Daigle, P., Dancause, K.N. \& Gadais, T. (2020). Forest

4 bathing: a narrative review of the effects on health for outdoor and environmental education

5 use in Canada. Journal of Outdoor and Environmental Education 23, 309-321.

6 https://doi.org/10.1007/s42322-020-00058-3

8 Title of manuscript: Forest bathing: a narrative review of the effects on health for the

9 use outdoor and environnemental education

\title{
11 Authors:
}

\section{Sandrine Mathias}

13 Clinical nurse in perinatality at the CLSC Pierrefonds (CIUSSS ODI);

14 Member of the International Society of Nature and Forest Medicine (INFOM) in Japan;

15 sandrine.ferfache@yahoo.fr

\section{Patrick Daigle Ph.D (c)}

18 Lecturer in the Department of Physical Activity Sciences at the Université du Québec à

19 Montréal (program in outdoor intervention);

20 Outdoor physical educator at Collège Jean-de-Brébeuf;

21 Daigle.patrick@uqam.ca

23 Kelsey Needham Dancause, Ph.D.

24 Professor

25 Département des sciences de l'activité physique

26 Université du Québec à Montréal

27 141, Avenue du Président Kennedy

28 Montréal (Québec), Canada, H2X 1Y4

29 Tel : 514-987-3000 \#5263

30 needham-dancause.kelsey@uqam.ca 
32 Tegwen Gadais, Ph.D. (corresponding author)

33 Professor

34 Département des sciences de l'activité physique

35 Université du Québec à Montréal

36 141, Avenue du Président Kennedy

37 Montréal (Québec), Canada, H2X 1Y4

38 Tel : 514-987-3000 \#3704

39 gadais.tegwen@uqam.ca

40

41 Author Contributions: S.M. and P.D. conducted the first articles researches and analyze,

42 they conceived and designed the first draft of the paper; T.G. helped to analyze and

43 complete the data, he rewrote and rearranged the draft in order to publication; K.N.D

44 contributed reagents/materials/analysis and gave expert critics to complete and improve

45 the quality of the paper.

46

47 Conflicts of Interest: "The authors declare no conflict of interest." 
48 Title of manuscript: Forest bathing: a narrative review of the effects on health for outdoor

49 and environmental education use in Canada

51 Key words (5-6)

52 Forest bath; Shinrin Yoku; interventions; Literature review; physiology; psychology.

\section{Abstract}

55 Education and health professionals from a range of disciplines seek alternatives to promote 56 well-being through nature. Shinrin Yoku, originating from Japan, means "forest baths" or 57 "taking in the forest atmosphere" and provides the opportunity to reconnect with nature 58 and its benefits, with great potential in Canada. This brief review aims to highlight the 59 potential for the use of Shinrin Yoku in the Canadian context of education and healthcare. 60 We conducted a narrative literature review including a search of four French and English 61 databases (Google Scholar, Pubmed, Scopus, Cairn) from 1985 to 2017. Then, we 62 classified 26 articles according to three main categories that emerged from the first reading 63 of the abstracts. Benefits of Shinrin Yoku have been classified into physiological, 64 psychological, and environmental categories. We analyzed the potential for use of this 65 alternative intervention by educators and health professionals in Canada. A growing body 66 of research suggests that Shinrin Yoku can have benefits on many aspects of an individual's 67 health and well-being. Given the resources already available in Canada, Shinrin Yoku 68 could be integrated into existing programs and interventions, and could provide another 69 option to educators and healthcare professionals seeking low-risk educational and 70 intervention alternatives for their students and patients. 


\section{Introduction}

Stress has widespread mental and physical health implications for individuals and

73 societies, and has become a major public health priority (Lovallo 2015). An increasing lack

74 of contact with nature is one currently discussed factor underlying psychosocial stress

75 among children and adults today (Cardinal 2010; Bowler et al. 2010). Youth who lack

76 contact with nature have the tendency to remain disconnected from nature as adults

77 (Larouche et al. 2016; Bowler et al. 2010). Thus, there is an interest and need for the

78 development and promotion of alternative interventions that help to connect youth with 79 nature.

80 Many educators, health professionals and social scientists, from a range of 81 disciplines, seek alternatives to traditional interventions or therapies to promote well-being 82 (Blanchet-Cohen and Elliot 2011; Bierle and Singletary 2008; Gatzemann et al. 2008;

83 Gadais et al. 2017). One such alternative named differently, sylvotherapy, forest therapy 84 or Shinrin Yoku, translates to "forest baths" and can also be interpreted as "taking in the 85 forest atmosphere" or "care by the forest." Sylvotherapy was born in Japan decades ago 86 (Tsunetsugu et al. 2010), and the country has established training and research programs 87 on the practice. It is part of the emerging trend of natural therapies that promote a 88 rediscovery of the benefits of nature. Sylvotherapy provides the opportunity to reconnect 89 with our true nature by removing ourselves for a time from the performance requirements 90 of the modern life (Papillon and Dodier 2011).

\section{Shinrin Yoku}

93 In theory, the idea of Shinrin Yoku or forest bathing is simple: a person simply 94 visits a natural area and walks in a relaxed way. Practitioners leave aside their phone, 95 camera or any other distractions to be fully present in the experience. They pause from 96 time to time to look more closely at a leaf or to notice the sensation of the path beneath 97 their feet. These leisurely walks under a forest canopy can be combined with guided 98 activities to help a person to open their senses, hone their intuition and experience the forest

99 as they never have before. Sessions of Shinrin Yoku are essentially designed by 100 incorporating mindfulness meditation practices and techniques of deep nature connection 101 mentoring. 
The calming, rejuvenating and restorative benefits of forest bathing have perhaps

103 always been known intuitively, but in recent decades scientific studies have gone some

104 way to revealing how simply being in wild areas has healing effects. A number of studies

105 from Japan and South Korea have demonstrated health benefits of spending time under the

106 canopy of the living forest (Han et al. 2016; Hansen et al. 2017; Kim et al. 2009; Lee et al.

107 2011; Li 2010; Li and Kawada 2011; Li et al. 2008). However, more investigation is

108 required. A systematic review conducted by Kamioka et al. (2012) showed the difficulty

109 of comparing results across studies because of poor methodological quality and a lack of

110 description in reports, while another conducted by Oh et al. (2017) focused on the benefits

111 of spending time in forests and highlighted positive health effects, but not enough to

112 generate clinical practice guidelines.

113 A training guide exists for Shinrin Yoku in Japan, but it is not translated into other

114 language and is thus not widely used internationally. The Association of Nature and Forest

115 Therapy Guides and Programs (Association of Nature and Forest Therapy Guides and

116 Programs 2019) offers some regular week-long training sessions in Europe and the United

117 States; and the first guides trained through this association are beginning to practice in

118 North America. However, research on the health effects of Shinrin Yoku remains limited

119 in Western countries (Morita et al. 2007; Hansen et al. 2017), and opportunities to practice

120 Shinrin Yoku and its potential to offer a positive intervention is still not widely known

121 among educators and health professionals in North America. However, given the public

122 interest in forest bathing, its simplicity and limited risk, and the potential for applying it in

123 Canada, a brief review to familiarize outdoor and environmental professionals with this

124 natural intervention is timely.

The emerging development of an intervention with high health potential in Canada

127 In Canada, the context and environment both seem well adapted to use Shinrin

128 Yoku. Forest and nature opportunities are vast in all Canadian provinces. Forests and 129 wooded areas constitute $40 \%$ of Canada's land area, and $92 \%$ of this is publicly owned

130 (Sustainable Forest Management in Canada 2019). Furthermore, forests have been and 131 remain an important part of Canada's economy and tradition, and are viewed as an integral 132 part of Canadian culture and lifestyle (Sustainable Forest Management in Canada 2019; 
133 Parks Canada 2019). As such, an extensive infrastructure exists to promote public access

134 to forests, such as Parks Canada, which manages a nationwide system of natural areas

135 across 39 natural regions (Parks Canada 2019); and provincial organizations such as the

136 Société des établissements de plein air du Québec (SÉPAQ, Society of outdoor recreation

137 establishments of Quebec), which manages its own system of 24 provincial parks, in

138 collaboration with Parks Canada (SÉPAQ 2019). These organizations are responsible for

139 both conservation of natural spaces, as well as promoting access to visitors, and provide an

140 existing network within which Shinrin Yoku could be implemented and promoted.

141 Even within urban areas, parks and green spaces are widely accessible in Canada.

142 Results from the 2013 "Households and the Environment Survey" showed 85\% of

143 Canadian households report that they lived close to a park or green space (Statistics Canada

144 2019). Practitioners could capitalize on these spaces to offer more regular opportunities for

145 Shinrin Yoku within cities. Finally, the growth of educational programs at all levels

146 specifically focused on environmental and outdoor education, and government support for

147 these programs, highlights not only the strong public interest in promoting access to natural

148 spaces, but is also resulting in a new growth of professionals trained to offer and adapt

149 these opportunities to a diverse clientele (Canadian Environmental Grantmakers' Network 150 2006).

151 We are currently witnessing the timid emergence of the practice of forest bathing, 152 promoted by organizations such as Shinrin Yoku Québec (Shinrin Yoku Quebec 2019) and 153 similar organizations offering holistic health workshops (Domaine VieNergie 2019).

154 Public interest in the practice is growing; in 2016, the journal La Presse published a popular 155 article on Shinrin Yoku (Allard 2016) and in 2017, Radio Canada published an interview

156 with the founder of Shinrin Yoku Québec (Radio Canada 2017). Some provincial parks

157 management organizations, such as Ontario Parks, have even begun to specifically discuss

158 forest bathing in their marketing and outreach campaigns (Ontario Parks 2019). The

159 arguments put forward by Japanese practitioners in favor of Shinrin Yoku seem to fit the

160 reality of Canadian provinces and the interests of education and healthcare professionals

161 to seek intervention alternatives.

162

163 Aim of the paper 
An exhaustive review of research on sylvotherapy and human health has been 165 recently published, highlighting the benefits of sylvotherapy on multiple health outcomes, 166 as well as its limitations (Hansen et al. 2017). Here, we strive to synthesize some key

167 physiological and psychological benefits of the therapy to promote its incorporation into 168 interventions, and to highlight the potential for the use of sylvotherapy in Canada. We hope 169 this review could help professionals in Canadian provinces to consider Shinrin Yoku as an 170 alternative to promote health and well-being throughout the country, outside of or in 171 collaboration with existing interventions in school, hospital or healthcare networks.

\section{Literature Review Methods}

174 A narrative literature review was conducted because it is a comprehensive, critical 175 and objective analysis of the current knowledge on a topic. This kind of review helps to 176 establish a theoretical framework and focus or context for our research on Shirin Yoku 177 topic. This narrative literature review was developed based on methods used in systematic 178 reviews (Cooper et al. 2018) and was conducted in two stages. The first stage consisted of 179 an exhaustive search (Step 1a; Table 1) of four French and English databases (Google 180 Scholar, Pubmed, Scopus, Cairn) for the period from 1985 to 2017. Databases were chosen 181 to cover a broad range of research across health sciences and education, to maximize the 182 likelihood of finding relevant articles. Searches were conducted using the following key 183 words: Sylvotherapy, Shinrin Yoku, tree therapy, forest baths, tree care, tree health, forest 184 health, forest therapy, forest care, nature care, nature therapy, stress and trees, stress and 185 nature, stress and forest. In total, 2194 articles were identified at this stage. Then (Step $186 \mathrm{1b}$ ), a first review of the titles and abstracts was completed by the first two authors of this 187 article in order to screen for relevant articles based on the inclusion criteria. Inclusion 188 critera were articles: a) published between 1985 up to 2017, b) peer-review, c) on Shirin 189 Yoku or Forest bath topic, d) open access online. We included peer-reviewed English190 language articles published after 1985 and before 2017. Articles that were not peer191 reviewed, and those not specifically focused on Shinrin Yoku or forest bathing, were 192 excluded. Excluding duplicates, 23 articles were selected and 3 were added from other 193 databases from recommendation of the third and the fourth authors of this paper. One of 194 these included a non-peer-reviewed work (Plaisance 1985) that we retained in the current 
195 review because of its importance in promoting awareness of potential health benefits of

196 forest bathing in Western countries. Thus, a total of 26 articles met the objectives of this

197 research and were included in this narrative review.

198

Table 1. (Step 1a) Preselection on four databases (2194 results)

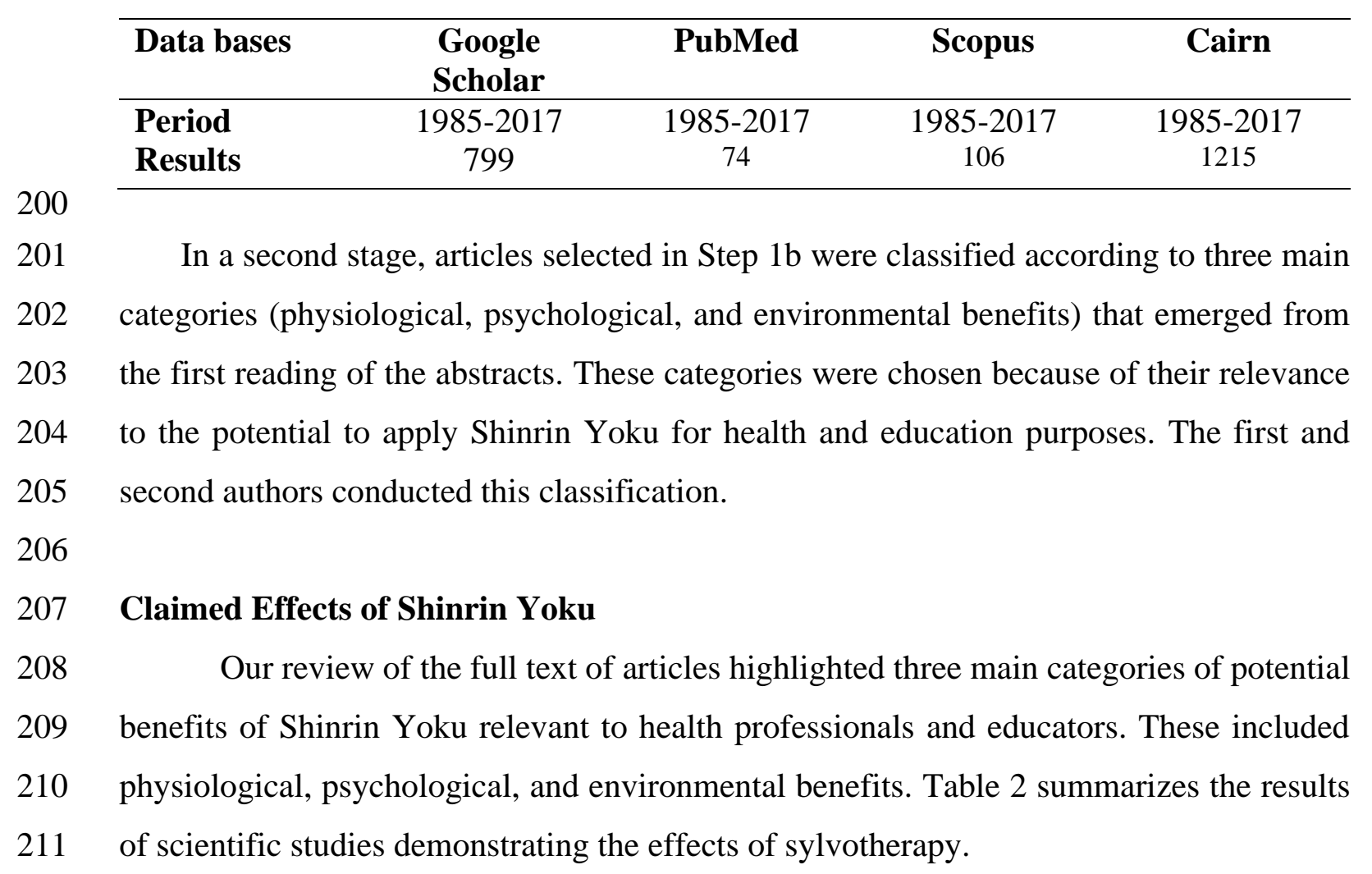


Table 2. Effects of silvicultural therapy according to the scientific literature

Benefits related to the environment
Limited presence of microbes and decreased pollutants
Exposure to better air quality (oxygen enriched air)
Liberation of antibiotic molecules by trees
Emission of essential oils
Colors and natural forms
Natural ambient sounds

Physiological effects

Strengthening the immune system

Strengthening the respiratory system

Decreased level of cortisol

Decreased heart rate and blood pressure

Increased number and activity of anti-cancer cells (NK)

Strengthening the activity of the nervous system

parasympathetic

Decreased activity of the sympathetic system

\begin{tabular}{c}
\hline Psychological effects \\
Decrease of stress \\
Improved nervous balance (control of emotions) \\
Decreased aggressiveness \\
Improved mood \\
Improved intellectual performance (memory) \\
Relaxation \\
\hline
\end{tabular}

214 Claims of health benefit related to the environment

215 Many benefits of sylvotherapy are thought to stem from direct contact with the 216 natural environment. First, the forest atmosphere is highly oxygenated and is largely free 217 of many of the environmental pollutants found in urban environments (Plaisance 1985;

218 Karjalainen et al. 2010; Escuté-Gasulla et al. 2015), as the deposition of pollutants to the 219 canopy and the reduction of air temperature through shading and transpiration in woodland 220 areas can improve air quality (Karjalainen et al. 2010; Nowak 2002).

221 Furthermore, trees naturally secrete antibiotic molecules that are found in the forest 222 atmosphere, including phytoncides, which are volatile antibiotic substances with 223 antimicrobial effects (Plaisance 1985). Recent studies show that phytoncides can induce 
224 lymphocyte activity in humans ( $\mathrm{Li}$ et al. 2006; Karjalainen et al. 2010), which might 225 represent an underlying mechanism linking forest bathing to enhanced immune function

226 (Li 2010). Also, exposure to negative ions in the forest atmosphere has been thought to 227 hold beneficial effects for human health (Plaisance 1985; Monce 2018). Recent studies 228 show few effects of negative ions on anxiety, mood, relaxation, and comfort, but show 229 some evidence that exposure to high-density negative air ionization predicts lower 230 depressive symptoms (Perez et al. 2013), which warrants further research.

Physiological effects

233 Sylvotherapy has long been thought to hold physiological benefits, strengthening 234 the respiratory system and cardiac function and helping to lower levels of cortisol and 235 blood pressure (Plaisance 1985). Recent studies have begun to confirm these benefits (Lee 236 et al. 2011; Li 2010; Li and Kawada 2011; Park et al. 2010). For example, one study 237 compared the effects of Shinrin Yoku and natural aromatherapy on immune function ( $\mathrm{Li}$ 238 2010). It was found that the activity and number of NK cells (natural killer cells: 239 lymphocytes in the same family as $\mathrm{T}$ and $\mathrm{B}$ cells) were significantly higher in the blood 240 after a stay in the forest, than in control samples. These benefits could last up to 30 days 241 after a stay in the forest of three days and two nights. Similar studies in cancer patients 242 have achieved similar results (Nakau et al. 2013). Interventions combining forest therapy, 243 horticultural therapy, yoga, and meditation in an urban green space showed improvements 244 in NK cell activity following sylvotherapy (Nakau et al. 2013). The conclusions highlight 245 the applicability of incorporating nature therapy into interventions, even in an urban 246 environment.

247 Studies of physiological effects of sylvotherapy indicate relationships with broad 248 indicators of stress. For example, some studies have indicated decreases of levels of the 249 stress hormone cortisol in saliva, arterial pressure, and heart rate following sylvotherapy 250 (Park et al. 2007; Park et al. 2010; Tsunetsugu et al. 2007; Tsunetsugu et al. 2010). 251 Similarly, the concentration of adrenaline in the urine was significantly lower after a 252 session of sylvotherapy ( $\operatorname{Li} 2010$ ). Exposure to the sounds of the forest may be one 253 underlying mechanism in this regard. Studies performed in a virtual forest in which sounds 254 specific to this environment were reproduced demonstrated that these sounds had a 
255 beneficial effect on stress (Annerstedt et al. 2013). Finally, brain activity in the prefrontal

256 region is significantly lower (suggesting a relaxing effect) in people who practice Shinrin

257 Yoku, unlike those who were offered the same activity - a walk - in urban areas (Park et

258 al. 2007).

Psychological effects

Many benefits of sylvotherapy are also demonstrate on a psychological level.

262 Environmental factors, such as the decrease in luminosity (particularly favorable for

263 meditation), the colors and forms of the natural environment, visual calm, and the

264 attenuation of "artificial" noises seem to have favorable repercussions for psychosocial

265 health (Plaisance 1985; Tsunetsugu et al. 2007). For example, studies in Japan show that

266 aggressiveness and depression scores measured using a mood scale decreased and vigor

267 increased following forest therapy. The higher the stress level before therapy, the more

268 effective the therapy on psychological outcomes (Morita et al. 2007). Results of a study

269 using the Profile of Mood States scale indicated that vigor scores increased, while scores

270 of anxiety, depression, and anger appeared diminished following sylvotherapy (Li et al.

271 2007; Li et al. 2008). Others have shown that spending two nights and three days in the

272 forest resulted in an increase in positive affect scores and a decrease in negative affect (Lee

273 et al. 2011). With a similar time period, studies comparing a group of participants who

274 stayed in the forest to a group that spent a stay in an urban area (Mao et al. 2012) showed

275 a significant improvement in mood and decreased stress among participants who were in

276 the forest. Others showed that subjects were in a more relaxed state following sylvotherapy

277 (Ochiai et al. 2015). One study demonstrated that a walk in an arboretum resulted in a

278 significant increase in memory, as well as better mood, than the group participating in an 279 urban walk (Berman et al. 2012).

280 The forest environment might provide an important addition to existing therapies

281 for patients with mental health disorders. For example, in the case of major depressive 282 disorders, the therapeutic effect of cognitive-behavioral treatments might be increased 283 when therapy is practiced in the forest (Kim et al. 2009). One study proposed a nine-day 284 Shinrin Yoku camp to assess depressive symptoms in a population of people with 285 alcoholism. It was found that depressive symptoms improved as a result of the therapy, and 
that participants with severe depression had an even greater improvement in their condition

287 (Shin et al. 2012). These findings were corroborated by another study that also found a 288 sharp decrease in depression and a significant improvement in quality of life related to 289 health status following forest therapy (Han et al. 2016). Whether used among healthy 290 individuals for the prevention of pathologies, or for patients already suffering from health 291 problems, current research is helping to put into perspective the potential benefits of this 292 therapy for psychological health.

\section{Discussion}

In this article we have presented the findings of a review of literature related to Shinrin Yoku or forest bathing, also referred to as sylvotherapy. Shinrrin Yoku appears to be an alternative intervention aimed at reconnecting populations with nature, which has benefits for stress reduction and other health outcomes. Because two recent reviews of research on sylvotherapy and human health have been recently published (Hansen et al. 2017; Oh et al. 2017), our focus was to synthesize some key benefits of Shinrin Yoku to promote its incorporation into interventions, and to highlight the potential for its use in could present new avenues for future research, but more studies are needed. Most people could likely benefit from the stress reduction and health effects associated with Shinrin Yoku, but impacts might be even greater at certain stages of life.

First, sylvotherapy could be implemented in school or community contexts with young people. A number of successful initiatives offering outdoor activities (e.g., forest, park, local community, farm) in schools have been shown to hold health benefits, and help

311 Scandinavian school movement Udeskole (Bentsen and Jensen 2012; Waite et al. 2016);

312 the Education Outside The Classroom (EOtC) (Beames et al. 2012) movement in the 313 United States (Kuo et al. 2018); the Learning in Natural Environment Program (Edwards314 Jones et al. 2018) and the Forest Schools (Waite et al. 2016) program in Great Britain; and 315 the Draussenschule in Germany (Becker et al. 2017; Sahrakhiz 2018).

316 Several studies also show academic benefits of such programs. Outdoor education 
317 promotes intrinsic motivation for students (Bølling et al. 2018), such that students are more 318 attentive and require less attention-related reinforcement following an outdoor learning 319 context (Kuo et al. 2018). Relationships between students are more positive and generally 320 supported by cooperative activities (Sahrakhiz 2018; Mygind 2009), and teachers have also 321 noted that outdoor education helps to develop more refined teacher-student relationships 322 (Barfod 2018).

323 Within the Canadian context, teachers seeking opportunities to plan nature 324 education or to teach outdoors tend to use pre-established nature programs such as Forest 325 schools (MacEachren 2013), Outward Bound (Lowan 2009), Outdoor Education 326 (Henderson and Potter 2001), or environmental education (Charland et al. 2009; Sauvé 327 2002). Both urban and more remote forest areas are used in these practices; for example, 328 nature schools and environmental education tend to take advantage of parks and natural 329 spaces within the community for students in primary schools, whereas programs for 330 secondary school or college students often include longer expeditions of up to a few days 331 in more remote areas (Pedretti et al. 2012). Some studies have highlighted similarities 332 between Japanese and Canadian teacher's views on science and nature, and cultural views 333 of humankind's relationship to nature (Aikenhead and Otsuji 2000). Given this context, 334 Shinrin Yoku appears relevant for being combined with other pedagogies that are already 335 in use by Canadian teachers. But more research on those potential effects are necessary.

336 Second, Shinrin Yoku could be very useful for working with populations of 337 pregnant women. The pregnancy period is a crucial moment that can have short, medium 338 and long term consequences for foetus and mother, both of whom are highly subject to 339 stress and environmental disruptions (Delassus 2011; Molénat and Roegiers 2011). 340 Interventions to reduce or to better manage stress during pregnancy could thus benefit well341 being of both mother and unborn child. Prenatal interventions focused on improving 342 maternal psychosocial health, such as mindfulness interventions (Dhillon et al. 2017) and 343 meditation and relaxation yoga (Gong et al. 2015), have been shown to reduce stress, 344 anxiety, and depression during pregnancy and potentially postnatally.

345 Shinrin Yoku could offer another low-risk intervention alternative to health 346 professionals working on the promotion of perinatal health (Molénat and Roegiers 2011). 347 Past research shows that exposure to green space is associated with reduced stress among 
348 the general population, and that among pregnant women, exposure to green space is

349 associated with lower risk of preterm birth and low birthweight (Twohig-Bennett and Jones

350 2018). Thus, forest bathing on its own, or in combination with other stress reduction

351 therapies, might have measurable effects on both maternal stress and on infant well-being.

352 It could be a method accessible at any stage of pregnancy, requiring relatively flat and

353 marked terrain to ensure that the activity takes place in safe conditions (Kuo 2015; Iwata

354 et al. 2016), but little in terms of equipment or experience. Because it is low risk, perinatal

355 nurses could implement Shinrin Yoku interventions early in pregnancy, and these might

356 provide an alternative that would be attractive to some patients who might not seek other

357 forms of treatment.

358 Following the Association of Nature and Forest Therapy Guides (Association of

359 Nature and Forest Therapy Guides and Programs 2019), many individual studies do

360 promote health benefits of forest therapy or forest bathing. However, more research on

361 Shirin Yoku and on the adaptation of training sessions for various fields of intervention is

362 required. The adaptation and application of Shinrin Yoku to the Canadian context requires

363 increased research attention in order to support better understanding: 1) amongst the public

364 in terms of the efficacy of this intervention; 2) of the practices of forest therapy; 3 ) of the

365 design of sites required for Shinrin Yoku activities such as walking and meditation; and 4)

366 how training and certification may help support future practitioners. We hope this review

367 could help professionals from education and healthcare in Canada, to better understand or

368 consider Shinrin Yoku as a possible alternative to promote health and well-being, in

369 collaboration with existing interventions in school, hospital or healthcare networks.

\section{5. Conclusion}

372 A growing body of research suggests that Shinrin Yoku can have benefits on many 373 aspects of an individual's health and well-being. This brief review aims to highlight new 374 perspectives for education and medicine related to outdoors and nature, and to familiarize 375 professionals with this therapy. This intervention approach appears realistic in the 376 Canadian context but more specific research on the topic is needed. In fact, it is likely 377 possible to incorporate Shinrin Yoku into many interventions in semi-natural spaces that 378 are already available near schools or health centers with carefully adaptations. Above all, 
379 it is hoped that by familiarizing health professionals, educators and researchers with 380 Shinrin Yoku, we might promote more detailed research on its incorporation into existing 381 interventions, its underlying mechanisms, and groups of patients that might particularly 382 benefit from this therapy. 


\section{References}

Aikenhead, G. S., \& Otsuji, H. (2000). Japanese and Canadian science teachers' views on science and culture. Journal of Science Teacher Education, 11(4), 277-299.

Allard, S. (2016). Shinrin-yoku: prendre un bain de forêt. La Presse. 10 May 2016.

Annerstedt, M., Jönsson, P., Wallergård, M., Johansson, G., Karlson, B., Grahn, P., et al. (2013). Inducing physiological stress recovery with sounds of nature in a virtual reality forest-Results from a pilot study. Physiology \& behavior, 118, 240-250.

Association of Nature and Forest Therapy Guides and Programs (2019). https://www.natureandforesttherapy.org/.

Barfod, K. S. (2018). Maintaining mastery but feeling professionally isolated: experienced teachers' perceptions of teaching outside the classroom. Journal of Adventure Education and Outdoor Learning, 18(3), 201-213.

Beames, S., Higgins, P., \& Nicol, R. (2012). Learning outside the classroom: Theory and guidelines for practice: Routledge.

Becker, C., Lauterbach, G., Spengler, S., Dettweiler, U., \& Mess, F. (2017). Effects of regular classes in outdoor education settings: a systematic review on students' learning, social and health dimensions. International journal of environmental research and public health, 14(5), 485.

Bentsen, P., \& Jensen, F. S. (2012). The nature of udeskole: outdoor learning theory and practice in Danish schools. Journal of Adventure Education \& Outdoor Learning, 12(3), 199-219.

Berman, M. G., Kross, E., Krpan, K. M., Askren, M. K., Burson, A., Deldin, P. J., et al. (2012). Interacting with nature improves cognition and affect for individuals with depression. Journal of affective disorders, 140(3), 300-305.

Bierle, S., \& Singletary, T. J. (2008). Environmental education and related fields in Idaho secondary schools. The Journal of Environmental Education, 39(3), 19-31.

Blanchet-Cohen, N., \& Elliot, E. (2011). Young children and educators engagement and learning outdoors: A basis for rights-based programming. Early education \& development, 22(5), 757-777.

Bølling, M., Otte, C. R., Elsborg, P., Nielsen, G., \& Bentsen, P. (2018). The association between education outside the classroom and students' school motivation: Results from a one-school-year quasi-experiment. International Journal of Educational Research, 89, 22-35.

Bowler, D. E., Buyung-Ali, L. M., Knight, T. M., \& Pullin, A. S. (2010). A systematic review of evidence for the added benefits to health of exposure to natural environments. BMC public health, 10(1), 456.

Canadian Environmental Grantmakers' Network (2006). Environmental education in Canada. Toronto.

Cardinal, F. (2010). Perdus sans la nature-Pourquoi les jeunes ne jouent plus dehors et comment y remédier. Montréal: Québec Amerique.

Charland, P., Potvin, P., \& Riopel, M. (2009). L'éducation relative à l'environnement en enseignement des sciences et de la technologie: Une contribution pour mieux Vivre ensemble sur Terre. Éducation et francophonie, 37(2), 63-78.

Cooper, C., Booth, A., Varley-Campbell, J., Britten, N., \& Garside, R. (2018). Defining the process to literature searching in systematic reviews: a literature review of guidance and supporting studies. BMC Med Res Methodol, 18(1), 85, 
Delassus, J.-M. (2011). Penser la naissance: Dunod.

Dhillon, A., Sparkes, E., \& Duarte, R. V. (2017). Mindfulness-Based Interventions During Pregnancy: a Systematic Review and Meta-analysis. [Review]. Mindfulness (N Y), 8(6), 1421-1437, doi:10.1007/s12671-017-0726-x.

Domaine VieNergie (2019). http://www.vienergie.ca/forettherapeutique. Accessed September 12019.

Edwards-Jones, A., Waite, S., \& Passy, R. (2018). Falling into LINE: school strategies for overcoming challenges associated with learning in natural environments (LINE). Education 3-13, 46(1), 49-63.

Escuté-Gasulla, X., Izquierdo, S., \& Rafa, M. (2015). Evidències de l'efecte del contacte amb els espais naturals sobre la salut de les persones. Butlletí de la Institució Catalana d'Història Natural, 115-118.

Gadais, T., Boulanger, M., Trudeau, F., \& Rivard, M.-C. (2017). Environments favorable to healthy lifestyles: A systematic review of initiatives in Canada. Journal of Sport and Health Science.

Gatzemann, T., Schweizer, K., \& Hummel, A. (2008). Effectiveness of sports activities with an orientation on experiential education, adventure-based learning and outdoor-education. Kinesiology, 40(2), 146-152.

Gong, H., Ni, C., Shen, X., Wu, T., \& Jiang, C. (2015). Yoga for prenatal depression: a systematic review and meta-analysis. BMC Psychiatry, 15, 14, doi:10.1186/s12888-015-0393-1.

Han, J.-W., Choi, H., Jeon, Y.-H., Yoon, C.-H., Woo, J.-M., \& Kim, W. (2016). The Effects of Forest Therapy on Coping with Chronic Widespread Pain: Physiological and Psychological Differences between Participants in a Forest Therapy Program and a Control Group. International journal of environmental research and public health, 13(3), 255.

Hansen, M. M., Jones, R., \& Tocchini, K. (2017). Shinrin-Yoku (Forest Bathing) and Nature Therapy: A State-of-the-Art Review. Int J Environ Res Public Health, 14(8), doi:10.3390/ijerph14080851.

Henderson, B., \& Potter, T. G. (2001). Outdoor Adventure Education in Canada: Seeking the Country Way In. Canadian Journal of Environmental Education, 6, 225-242.

Iwata, Y., Dhubháin, Á. N., Brophy, J., Roddy, D., Burke, C., \& Murphy, B. (2016). Benefits of group walking in forests for people with significant mental ill-health. Ecopsychology, 8(1), 16-26.

Kamioka, H., Tsutani, K., Mutoh, Y., Honda, T., Shiozawa, N., Okada, S., et al. (2012). A systematic review of randomized controlled trials on curative and health enhancement effects of forest therapy. Psychology research and behavior management, 5, 85 .

Karjalainen, E., Sarjala, T., \& Raitio, H. (2010). Promoting human health through forests: overview and major challenges. Environmental health and preventive medicine, 15(1), 1.

Kim, W., Lim, S.-K., Chung, E.-J., \& Woo, J.-M. (2009). The effect of cognitive behavior therapy-based psychotherapy applied in a forest environment on physiological changes and remission of major depressive disorder. Psychiatry investigation, 6(4), 245-254. 
Kuo, M. (2015). How might contact with nature promote human health? Promising mechanisms and a possible central pathway. Frontiers in psychology, 6, 1093.

Kuo, M., Browning, M. H., \& Penner, M. L. (2018). Do lessons in nature boost subsequent classroom engagement? Refueling students in flight. Frontiers in psychology, 8 , 2253.

Larouche, R., Garriguet, D., Gunnell, K. E., Goldfield, G. S., \& Tremblay, M. S. (2016). Outdoor time, physical activity, sedentary time, and health indicators at ages 7 to 14: 2012/2013 Canadian Health Measures Survey: Statistics Canada.

Lee, J., Park, B.-J., Tsunetsugu, Y., Ohira, T., Kagawa, T., \& Miyazaki, Y. (2011). Effect of forest bathing on physiological and psychological responses in young Japanese male subjects. Public health, 125(2), 93-100.

$\mathrm{Li}, \mathrm{Q}$. (2010). Effect of forest bathing trips on human immune function. Environmental health and preventive medicine, 15(1), 9-17.

Li, Q., \& Kawada, T. (2011). Effect of forest therapy on the human psycho-neuroendocrino-immune network. Nihon eiseigaku zasshi. Japanese journal of hygiene, 66(4), 645-650.

Li, Q., Morimoto, K., Kobayashi, M., Inagaki, H., Katsumata, M., Hirata, Y., et al. (2008). A forest bathing trip increases human natural killer activity and expression of anticancer proteins in female subjects. J Biol Regul Homeost Agents, 22(1), 45-55.

Li, Q., Morimoto, K., Nakadai, A., Inagaki, H., Katsumata, M., Shimizu, T., et al. (2007). Forest bathing enhances human natural killer activity and expression of anti-cancer proteins. Int $J$ Immunopathol Pharmacol, $20(2$ Suppl 2), 3-8, doi:10.1177/03946320070200S202.

Li, Q., Nakadai, A., Matsushima, H., Miyazaki, Y., Krensky, A. M., Kawada, T., et al. (2006). Phytoncides (wood essential oils) induce human natural killer cell activity. Immunopharmacol Immunotoxicol, 28(2), 319-333, doi:10.1080/08923970600809439.

Louv, R. (2008). Last child in the woods: Saving our children from nature-deficit disorder: Algonquin Books.

Lovallo, W. R. (2015). Stress and Health: Biological and Psychological Interactions, 3rd Edition. London: Sage Publications.

Lowan, G. (2009). Exploring place from an Aboriginal perspective: Considerations for outdoor and environmental education. Canadian Journal of Environmental Education (CJEE), 14, 42-58.

MacEachren, Z. (2013). The Canadian forest school movement. Learning Landscapes, 7(1), 219-233.

Mao, G. X., Lan, X. G., Cao, Y. B., Chen, Z. M., He, Z. H., Lv, Y. D., et al. (2012). Effects of short-term forest bathing on human health in a broad-leaved evergreen forest in Zhejiang Province, China. Biomedical and Environmental Sciences, 25(3), 317324.

Molénat, F., \& Roegiers, L. (2011). Stress et grossesse: quelle prévention pour quel risque?

Monce, L. (2018). Ces arbres qui nous veulent du bien: A la découverte des bienfaits de la sylvothérapie. Paris: Dunod.

Morita, E., Fukuda, S., Nagano, J., Hamajima, N., Yamamoto, H., Iwai, Y., et al. (2007). Psychological effects of forest environments on healthy adults: Shinrin-yoku 
(forest-air bathing, walking) as a possible method of stress reduction. Public health, 121(1), 54-63.

Mygind, E. (2009). A comparison of childrens' statements about social relations and teaching in the classroom and in the outdoor environment. Journal of Adventure Education \& Outdoor Learning, 9(2), 151-169.

Nakau, M., Imanishi, J., Imanishi, J., Watanabe, S., Imanishi, A., Baba, T., et al. (2013). Spiritual care of cancer patients by integrated medicine in urban green space: a pilot study. Explore: The Journal of Science and Healing, 9(2), 87-90.

Nowak, D. J. (2002). The effects of urban trees on air quality. Syracuse, NY: USDA Forest Service.

Ochiai, H., Ikei, H., Song, C., Kobayashi, M., Miura, T., Kagawa, T., et al. (2015). Physiological and psychological effects of a forest therapy program on middle-aged females. International journal of environmental research and public health, 12(12), 15222-15232.

Oh, B., Lee, K. J., Zaslawski, C., Yeung, A., Rosenthal, D., Larkey, L., et al. (2017). Health and well-being benefits of spending time in forests: systematic review. Environmental health and preventive medicine, 22(1), 71.

Ontario Parks (2019). Healing in the forest: a guide to forest bathing. https://www.ontarioparks.com/parksblog/guide-forest-bathing/. Accessed September 12019.

Papillon, P., \& Dodier, R. (2011). Les forêts périurbaines: des usages récréatifs à l'espace prophylactique. Journal of Alpine Research| Revue de géographie alpine(99-3).

Park, B. J., Tsunetsugu, Y., Kasetani, T., Hirano, H., Kagawa, T., Sato, M., et al. (2007). Physiological effects of shinrin-yoku (taking in the atmosphere of the forest)using salivary cortisol and cerebral activity as indicators-. Journal of Physiological Anthropology, 26(2), 123-128.

Park, B. J., Tsunetsugu, Y., Kasetani, T., Kagawa, T., \& Miyazaki, Y. (2010). The physiological effects of Shinrin-yoku (taking in the forest atmosphere or forest bathing): evidence from field experiments in 24 forests across Japan. Environmental health and preventive medicine, 15(1), 18-26.

Parks Canada (2019). National Parks. https://www.pc.gc.ca/en/pn-np/introduction.

Pedretti, E., Nazir, J., Tan, M., Bellomo, K., \& Ayyavoo, G. (2012). A Baseline Study of Ontario Teachers' Views of Environmental and Outdoor Education. Pathways: The Ontario Journal of Outdoor Education, 24(2), 4-12.

Perez, V., Alexander, D. D., \& Bailey, W. H. (2013). Air ions and mood outcomes: a review and meta-analysis. BMC Psychiatry, 13, 29, doi:10.1186/1471-244X-13-29.

Plaisance, G. (1985). Forêt et santé: guide pratique de sylvothérapie: découvrez les effets bienfaisants de la forêt sur le corps et l'esprit: Éditions Dangles.

Radio Canada (2017). Le shinrin-yoku, ce « bain de forêt » thérapeutique antistress: Entrevue avec Bernadette Rey.

Sahrakhiz, S. (2018). The 'outdoor school'as a school improvement process: empirical results from the perspective of teachers in Germany. Education 3-13, 46(7), 825837.

Sauvé, L. (2002). L'éducation relative à l'environnement: possibilités et contraintes. Connexion, La revue d'éducation scientifique, technologique et environnementale de l'UNESCO, 27(1/2), 1-4. 
567 SÉPAQ (2019). Société des établissements de plein air du Québec. $568 \quad$ https://www.sepaq.com/pq/index.dot?language _id=1.

569 Shin, W. S., Shin, C. S., \& Yeoun, P. S. (2012). The influence of forest therapy camp on depression in alcoholics. Environmental health and preventive medicine, 17(1), 7376.

Shinrin Yoku Quebec (2019). http://www.shinrin-yoku-quebec.org. Accessed September 12019.

Statistics Canada (2019). Canadians and Nature: Parks and green spaces, 2013. https://www150.statcan.gc.ca/n1/pub/16-508-x/16-508-x2015002-eng.htm. Accessed September 12019.

Sustainable Forest Management in Canada (2019). Canada's Forests. https://www.sfmcanada.org/en/. Accessed September 12019.

Tsunetsugu, Y., Park, B.-J., Ishii, H., Hirano, H., Kagawa, T., \& Miyazaki, Y. (2007). Physiological effects of Shinrin-yoku (taking in the atmosphere of the forest) in an old-growth broadleaf forest in Yamagata Prefecture, Japan. Journal of Physiological Anthropology, 26(2), 135-142.

Tsunetsugu, Y., Park, B.-J., \& Miyazaki, Y. (2010). Trends in research related to "Shinrinyoku"(taking in the forest atmosphere or forest bathing) in Japan. Environmental health and preventive medicine, 15(1), 27.

Twohig-Bennett, C., \& Jones, A. (2018). The health benefits of the great outdoors: A systematic review and meta-analysis of greenspace exposure and health outcomes. Environ Res, 166, 628-637, doi:10.1016/j.envres.2018.06.030.

Waite, S., Bølling, M., \& Bentsen, P. (2016). Comparing apples and pears?: a conceptual framework for understanding forms of outdoor learning through comparison of English Forest Schools and Danish udeskole. Environmental Education Research, 22(6), 868-892. 